workshop. $97 \%$ believe that this educational intervention will improve the diagnostic approach to patients with suspected RA.

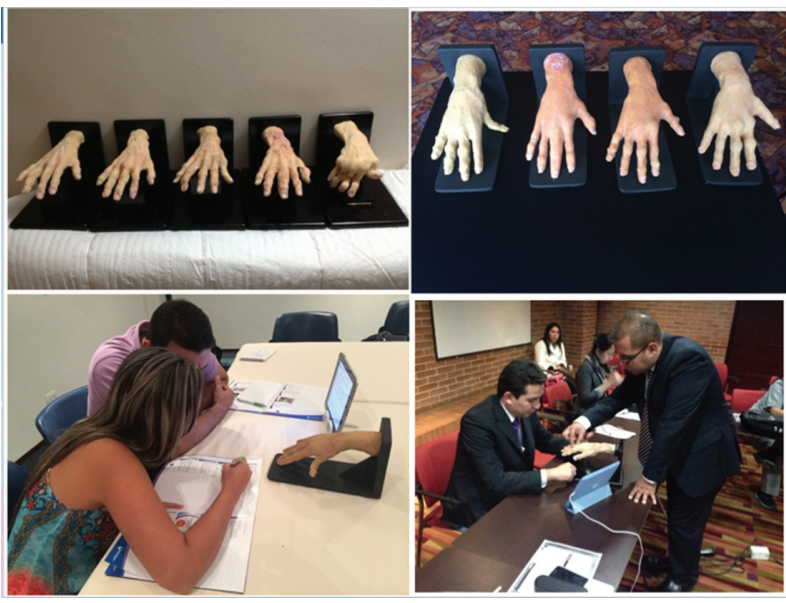

Abstract AB1393 - Figure 1

Conclusions: The present research is a pioneer and innovator in the field of rheumatology education. We have shown the usefulness of clinical simulation by an improvement in the diagnostic sensitivity towards the diagnosis of RA, highlighting the semiology as a key element at the time of making the diagnosis. A significant decrease in the total number of exams requested for each of the clinical cases analysed was documented, which can have a positive effect on costs for the national health systems.

REFERENCE:

[1] Fernández-Ávila DG, Ruiz ÁJ, Gil F, Mora SA, Tobar C, Gutiérrez JM, Rosselli D. The effect of an educational intervention, based on clinical simulation, on the diagnosis of rheumatoid arthritis and osteoarthritis.Musculoskeletal Care. 2017;1-5.DOI: 10.1002/msc.1228

Disclosure of Interest: None declared

DOI: 10.1136/annrheumdis-2018-eular.6124

\section{AB1394 DEVELOPMENT OF A SERIES OF SIMULATORS AND DESIGN OF A COURSE BASED ON CLINICAL SIMULATION, FOR TEACHING DIAGNOSTIC APPROACH TO PATIENTS WITH JOINT PAIN AND SUSPECTED RHEUMATIC DISEASES}

S.A. Mora Alfonso ${ }^{1,2}$, D.G. Fernández Ávila ${ }^{2,3}$, on behalf of Sociedad para la Investigación, atención y educación en enfermedades reumáticas INVEDER SAS. ${ }^{1}$ Rheumatology, Universidad de la Sabana; ${ }^{2}$ Rheumatology, Sociedad para la Investigación, atención y educación en enfermedades reumáticas INVEDER SAS ${ }^{3}$ Pontificia Universidad Javeriana - Hospital Universitario San Ignacio. Bogotá, Colombia, Bogotá, Colombia

Background: The teaching of clinical approaches to patients with RA (Rheumatoid Arthritis) and SpA (Spondyloarthritis) requires both a practical and a theoretical component, and there are difficulties in having real patients for teaching Previously our group has shown the use of clinical simulation in rheumatology, an area in which it had not been used. We demonstrated the effectiveness of an educational intervention based on clinical simulation to improve the diagnostic approach to RA1. Thus, the idea emerged to apply clinical simulation in the field of RA and SpA teaching. An exhaustive search of the scientific literature through May 2017 revealed no works on clinical simulation for rheumatic diseases. The simulation models recieved a patent for intellectual property and utility for education, with a 10-year protection.

Methods: Design and installation a life-sized mannequin and separate anatomical parts (five hands, six fingers, three feets) with a set of semiological findings for SpA and RA

Results: We have designed unique simulation models -a life-sized mannequin and separate anatomical parts (five hands, six fingers, three feets) with a set of semiological findings for SpA and RA. Each simulator (artificial hands, finger or feet) has natural size and was made of epoxy resin. The simulators ligaments, muscles and support tissues were made of silicone rubber, and the simulator was covered by polyurethane skin on an acrylic support. Each hand, feet or finger has various semiological findings of $\mathrm{SpA}$ and RA (synovitis, pannus, enthesitis, dactylitis, joint deformities, classical findings of psoriatic nails and psoriatic plaques) made from materials that generated textures very similar to those found in real patients. Learning is transferred from interacting with the models by using the sense of touch to feel and perceive how the clinical manifestations of the diseases are. The workshops comprise a six-stage rotation where the anatomical models are accompanied by a brief video describing a clinical case. After viewing the video participants interacts with the models to understand and recognise each of the clinical features of SpA and RA, as if in a real patient. Whereas in regular work shops where knowledge is transfer through a keynote speaker and visual images, this one is a total learning by the experience of touching and feeling.

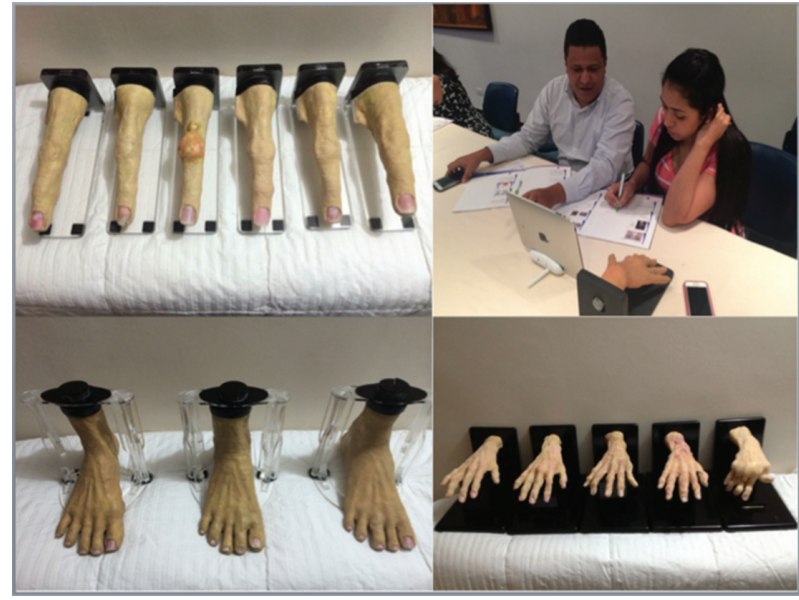

Abstract AB1394 - Figure 1

Conclusions: The present research is a pioneer and innovator in the rheumatology education. In this vein, we hope that this research is the first in the context of a new way of teaching rheumatology, educational process and eventually will have a global projection that allows the creation of a course for early diagnosis and initial treatment of rheumatic diseases, similar to what is currently done in cardiology with ACLS and in trauma with ATLS

\section{REFERENCE:}

[1] Fernández-Ávila DG, Ruiz ÁJ, Gil F, Mora SA, Tobar C, Gutiérrez JM Rosselli D.The effect of an educational intervention, based on clinical simulation, on the diagnosis of rheumatoid arthritis and osteoarthritis.Musculoskeletal Care. 2017;1-5.DOI: 10.1002/msc.1228

Disclosure of Interest: None declared DOI: 10.1136/annrheumdis-2018-eular.6149

\section{AB1395 EFFECT OF AN EDUCATIONAL INTERVENTION BASED ON CLINICAL SIMULATION IN THE DIAGNOSIS OF SPONDYLOARTHRITIS (SPA) FROM GENERAL PRACTITIONERS, A STUDY BEFORE AND AFTER}

S.A. Mora Alfonso ${ }^{1,2}$, D.G. Fernández Ávila ${ }^{2,3}$, on behalf of Sociedad para la Investigación, atención y educación en enfermedades reumáticas INVEDER SAS. ${ }^{1}$ Rheumatology, Universidad de la Sabana; ${ }^{2}$ Rheumatology, Sociedad para la Investigación, atención y educación en enfermedades reumáticas INVEDER SAS; ${ }^{3}$ Pontificia Universidad Javeriana - Hospital Universitario San Ignacio. Bogotá, Colombia, Bogotá, Colombia

Background: Previously our group has shown the use of clinical simulation in rheumatology. We demonstrated the effectiveness of an educational intervention based on clinical simulation to improve the diagnostic approach to RA1, so we wanted to apply this same principle in the learning of SpA (Spondyloarthritis).

Objectives: This paper wants to quantify the rate of improvement in the diagnosis of Spondyloarthritis $(\mathrm{SpA})$ among a group of general practitioners who receive an educational intervention based on clinical simulation.

Methods: Intervention study before and after

Results: 102 general practitioners received an educational intervention based on clinical simulation. The topic of this educational intervention was Spondyloarthritis $(\mathrm{SpA})$. A workshop that includes clinical simulation models of feet, fingers and a mannequin created for this purpose was created, based on the strategy of problem-based learning. The workshop lasted 5 hours, it was divided into two parts: the first was about the of the clinical approach of joint pain and lumbar pain diag nosis and relevant aspects of SpA. In this first part, besides the theoretical support 